J. Asiat. Soc. Bangladesh, Sci. 40(1): 27-37, June 2014

\title{
WOMEN HEALTH AND DISEASE PATTERN IN THE RURAL AREAS OF BANGLADESH: A CASE STUDY ON HAIMCHAR UPAZILA UNDER CHANDPUR DISTRICT
}

\author{
ALAK PAUL, MD. MAHBUB MURSHED AND SAMIA AKTHER \\ Department of Geography and Environmental Studies \\ University of Chittagong, Chittagong-4331, Bangladesh
}

\begin{abstract}
The present research has undertaken to understand the women health scenario in a remote rural char land of the country and their health awareness with hygienic practices. Most of the women in the study area were found illiterate and not fully conscious about health and health care aspects. The overall health condition of women in the study area was found very poor and affected various diseases from lack of personal attention and adequate health care. It is evident that most of the women age ranging from 26 to 45 in the study area were the most sufferer of different number of diseases like fever, diarrhoea, skin diseases, asthma, reproductive tract infections (RTI) and various gynecological diseases. It was also identified that, water and sanitation related diseases are very common among the women of the study area which may be the result of using unsafe water and unhygienic sanitation practices.
\end{abstract}

Key words: Women health, Disease pattern, Health Care, FGD

\section{Introduction}

Health is a basic requirement to improve the quality of life. The international declaration of Health rights proclaims that "the enjoyment of the highest attainable standard of health is one of the fundamental rights of every human being" (Perry 2000). Women's health involves their emotional, social, spiritual, and physical well-being and is determined by the social, political, and economic context of their lives, as well as biology (Navarro and Shi 2001). Globally, $43 \%$ of all women and $56 \%$ (on average) of pregnant women suffer from iron-deficiency anemia (Allen 2000). Every year, about 10 million women endure life-threatening complications during pregnancy and childbirth, sometimes leading to long term disability (WHO 2013). The major health problems of women are related to malnutrition and to environmental factors which are disease-related and mostly preventable (Blair 1980 and Helweg-Larsen and Kruse 2003).

Women are the most neglected and deprived section of the society in Bangladesh. Women health and health care is little or no attended in the traditional society especially in the rural areas of the country. Women's health complexities and problems are among the major health problems in Bangladesh. Women health status in Bangladesh is low, poverty coupled with social and cultural practices, beliefs and practices, gender based violence, lack of educations and inadequate health care facilities result to women's poor health and place them in a state that affects their reproductive health (Karmakar 2005). 
The rural women are the most vulnerable section of the society and usually suffer from ill-health. The health of women is a crucial factor in the health of children, but gender discrimination leaves women particularly vulnerable to disease and death (Whittle and Inhorn 2001).

The objective of the study is to identify the women health status and their disease pattern as well as the social and environmental factors responsible for the disease causing of women in a remote rural char area of Haimchar Upazila under Chandpur district.

\section{Materials and Methods}

The Study Area: The study was conducted on three char (riverine islands) villages of Nilkamal Union of Haimchar Upazila under Chandpur district (Fig. 1) namely Mazir Bazaar Char, Miar Bazaar Char and Bangla Bazaar Char. The studied union is an ideal example of remote rural area which is dissected by lower Meghna River into many parts. Disfavors of geographical location and poor communication facilities made the area a backward one which led a miserable life to its inhabitants. Almost half of the respondents (49\%) found illiterate where agriculture and fishing are the major occupations of the inhabitants in the study area though according to the respondents, these two occupations fail to ensure their all the year employment and income as the chars remain flooded almost half of the year and agriculture is not possible at that time (Table 1).

Table 1. Respondent's Level of Literacy and Income.

\begin{tabular}{lccc}
\hline Educational Status & Percentage & Income Level (in Taka) & Percentage \\
\hline Illiterate & 49 & Less than 2000 & 9 \\
Primary & 44 & $2000-5000$ & 85 \\
Secondary & 7 & $5100-8000$ & 6 \\
\hline
\end{tabular}

Source: Field Survey, 2011

Methodology: To conduct this research both primary and secondary data were collected. The study was focused on different age groups (for example, 15-25; 26-35; 36-45; 46-60; and $60+$ ) of women to know their health problems and causes. It was completed mainly by primary field survey. Moreover, secondary data sources both published and unpublished materials such as books, thesis papers, articles, magazines, different govt. and non govt. project works etc. were consulted to enrich the research. To achieve the aim and objectives of this study, both quantitative and qualitative approaches (questionnaire, FGD, case study etc.) were followed for getting the disease quantity and inside of women's health respectively. The respondents of the study were women of different age groups (from 15 to over 60 years) who were selected through simple random sampling from the local communities. 
A significant numbers of Focus Group Discussion (FGDs), in-depth interviews, case studies were conducted among the older women, housewives those who were suffering from various disease, and local govt. representatives (UP chairman, members). Opinions were taken from some specialized doctors of Chandpur Sadar Hospital, Upazila Health Officer and other health experts who were dealing with the women health problems and disease. Mainly women in the sampling frame were interviewed with a structured questionnaire. Following a representative sampling size $(10 \%$ of the total households in the surveyed units), the total number of questionnaires were 150 . In other words, 50 questionnaires were used for each char among the individual housewives or aged women. This method was helped to understand the disease pattern of the respondents in the study area.

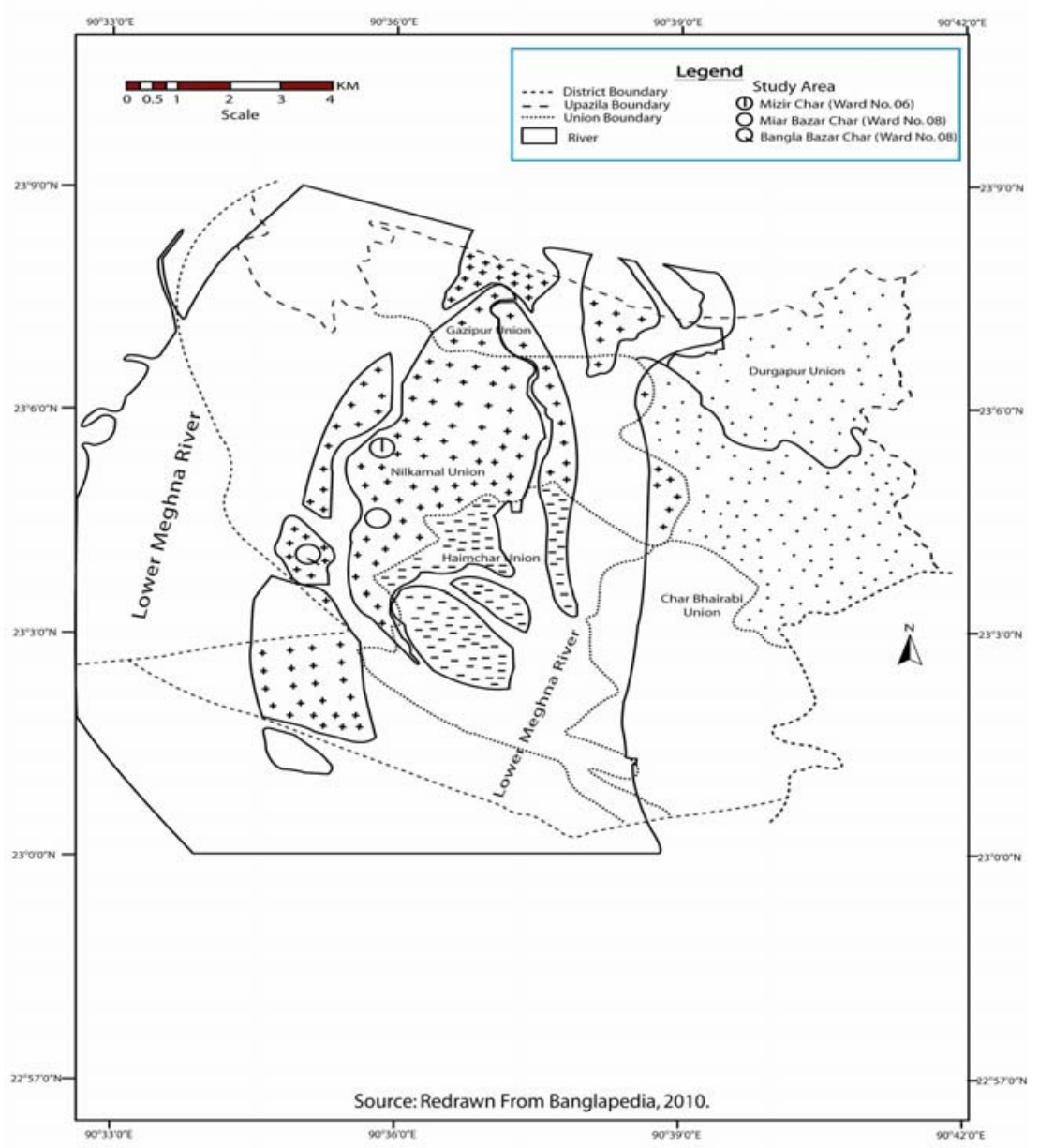

Fig. 1. Study Area Map (Nilkamal Union, Haimchar Upazila, Chandpur). 
The collected quantitative data were analyzed by using Microsoft excel program. Frequency analysis including single and multi response tables as well as contingency tables and analysis was done to identify relationship among variables. In few cases, data were varied due to open ended questions and multi response of the respondent. Different techniques have been followed to process and analysis data and used necessary tables, figures, graphs, charts and maps which also prepared the report.

The "grounded theory", a popular qualitative approach was extensively used in this study for analyzing and describing FGD, case study data. This approach was used as a form of field-study that systematically applied procedural steps to develop an explanation about the Environmental, geographical, social and economical aspects of health condition of rural women in Bangladesh.

\section{Results and Discussion}

Disease Pattern of the Respondents: The lack of safe water supply and basic sanitation facilities coupled with malnutrition, poor and inadequate housing, and other socioeconomic factors, particularly poverty have resulted in high morbidity and mortality within communities in the rural areas of Bangladesh (Aziz et. al. 1990 and Koenig et al. 2003). The present study area located in the islands (chars) of Haimchar upzila under Chandpur district is an ideal example of remote rural area of Bangladesh, where the backward communication is a great barrier in resource and service flow in the area. Low economic condition results low living standard, illiteracy, unconsciousness and poor health condition. Almost half of the respondents (49\%) found illiterate, and the illiteracy is one of the important barriers to become aware about health problems and personal health care issues. Agriculture and fishing are the major occupations of the inhabitants in the study area though according to the respondents, these two occupations fail to ensure their all the year employment and income as the chars remain flooded almost half of the year and agriculture is not possible at that time (see Table 1).

Thus extreme poverty and miserable lives prevail almost whole char areas and the women are the most vulnerable group to face the stresses of basic needs due to the family insolvency which was evident from their long breath during focus group discussion with the char women and it is their fate that the women of remote rural areas have to struggle with diseases from their childhood to death,.

The common scenario of women health in the study area is poor, suffering from malnutrition and parasitism and chronic ill health from lack of personal attention and adequate health care. The state of overall women health is reflected in different types of disease occurring. The disease pattern of the respondents in the char area are shown in the Fig. 2. 


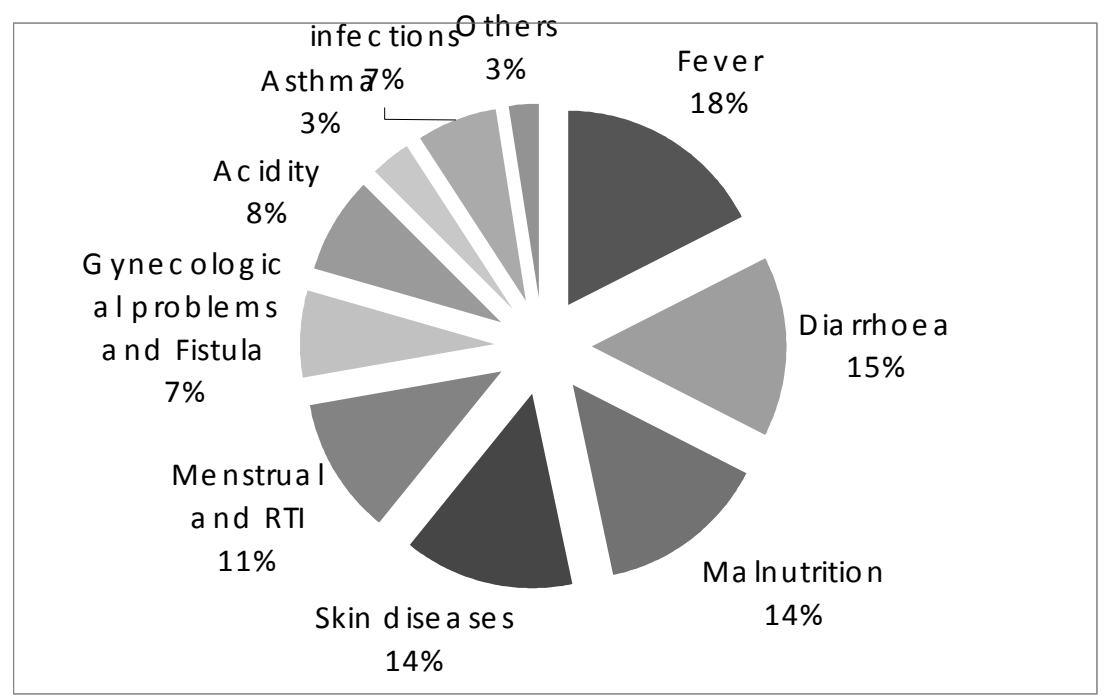

Fig. 2. Women Disease Pattern in the Study Area.

\{Source: Field data, 2011. (Multiple Answers Considered)\}

The most common diseases reported by women of different age groups from the study area are fever, followed by diarrhoea, malnutrition (the respondents termed it as weakness), skin diseases; and menstrual and reproductive tract infections (RTI). Besides, the respondents also mentioned about gynecological complicacies, acidity, asthma, eye infections etc (Please see Table 2).

Table 2. Pattern of diseases suffered by women in the study area (Last 6 months counting in frequency).

\begin{tabular}{llllllllll}
\hline $\begin{array}{l}\text { Age } \\
\text { Group }\end{array}$ & $\begin{array}{l}\text { Fever/ } \\
\text { Typhoid }\end{array}$ & $\begin{array}{l}\text { Diarrhea } \\
\text { Eye } \\
\text { infection disease }\end{array}$ & $\begin{array}{l}\text { Skin } \\
\text { and RTI }\end{array}$ & $\begin{array}{l}\text { Menstrual } \\
\text { and } \\
\text { Hepatitis }\end{array}$ & $\begin{array}{l}\text { Asthma } \\
\text { ition }\end{array}$ & $\begin{array}{l}\text { Malnutr Others } \\
\text { indity }\end{array}$ \\
\hline $15-25$ & 22 & 30 & 6 & 32 & 43 & 10 & 3 & 25 & 6 \\
$26-35$ & 43 & 40 & 20 & 38 & 44 & 24 & 5 & 34 & 8 \\
$36-45$ & 38 & 26 & 9 & 25 & 22 & 16 & 5 & 23 & 10 \\
$46-60$ & 8 & 5 & 5 & 3 & - & 7 & 6 & 7 & 4 \\
$60+$ & 3 & 2 & 3 & 2 & - & 2 & 3 & 2 & 2 \\
\hline
\end{tabular}

Source: Field Survey, 2011

Fever: Fever is the most common health problem as reported by all ages of women in the char area. From the survey it is recorded that the highest number of respondents $(17.15 \%)$ found suffering from fever frequently and they do not take proper treatment for the disease as the respondent mentioned that they do not treat fever as any disease or health 
problem rather they consider the causing of fever as a simple matter. According to the Health Officer of Haimchar Upazila Health Complex, fever is the symptom of any physical disorder. He added that the women of char areas are always overburdened with their household activity and in addition to that they have to help their husbands in the fields even under hot sun, rains or early cold mornings. Their ill health condition fail to support the hard works and they frequently suffer from fever. Due to extreme poverty they do not able to fulfill their nutritional demands and they are affected by fever. A housewife from the study area Bangla Bajar Char named Jamela Begum (27) told in this way, "We do work in all seasons in the chars and have to suffer both in summer and winter so we live with diseases without any medicine as we are poor by born".

Diarrhoeal Diseases: About 15.12\% women of the study area reported that they commonly suffer from diarrhoea. The number is high in regarding to the total disease burden of respondents in the study area. Diarrhoea is water borne disease and women are more involved with water use and sanitation than man. In the char area majority of the women are illiterate and they are not aware of their hygiene. Use of unsafe water and inadequate sanitation facilities attribute diarrhoeal diseases to the women of remote rural areas. From the survey it was found that, $88 \%$ respondents do not wash their hands properly after defecation and only $12 \%$ found to practice hygiene rules (Fig. 3).

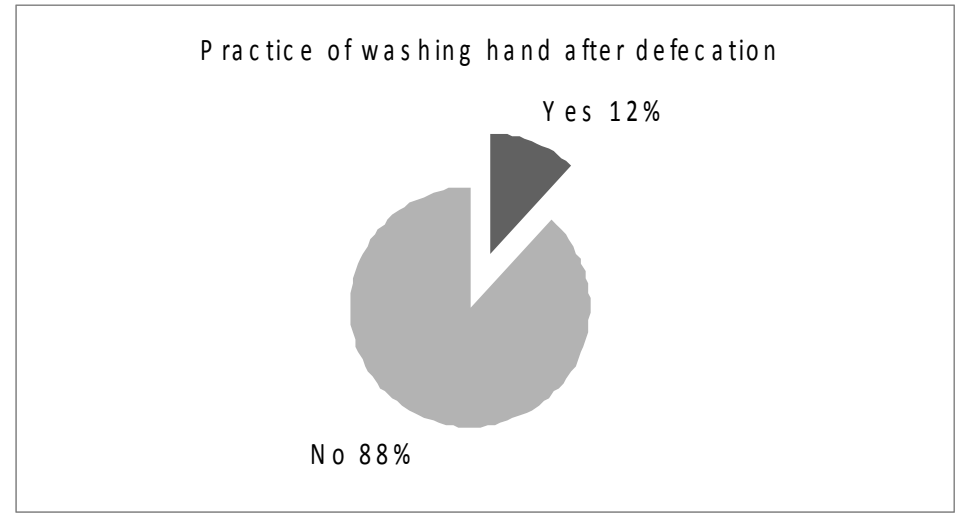

Fig. 3. Women practice of washing hand with soap after defecation in the study area (Source: Field data, 2011).

Like other remote rural areas of Bangladesh, there found no hygienic sanitary latrines in the study area rather the latrines are typical hanging pattern made simply with bamboo and jute sack or polythene side covers with very weak structure. The latrines found hanging on nearby open ditches or ponds and the pond waters are used by the inhabitants. The lack of sanitary latrine and hygienic toilet practices are strongly related to diarrhoeal diseases. The respondent who has no toilet facilities in the study area they often get off 
defecation in the open spaces. The children are usually toileted in the open yard or back of the houses. This type of latrine contaminates the water bodies, because rain washes the excreta matter into the pond. In the char area, all respondents use river water for their cooking, bathing, washing, animal bathing and other purposes. From the field survey it is induced that anthropogenic causes such as domestic uses, cloth washing, throwing human and animal excreta, and animal bathing purpose etc. are the major factors of water pollution in the char area. They cook using the river water but before cooking they do not purify or boil the water. At that time respondents are mostly affected from water-borne diseases (diarrohea, cholera etc) for using their polluted water.

Skin Diseases: Lack of physical cleanliness, unhygienic living and personal attention widespread skin disease found among the different women age groups in the study area. About $14 \%$ of the respondent women mentioned about various types of chronic skin diseases. According to Haimchar Upazila Health Complex, more than $80 \%$ aged women are suffering from various skin diseases.

The problem found very acute in the mid aged women. Some of the respondent mentioned that not only herself, their other family members are also suffering from this contagious disease. Poor sanitation, lack of cleanliness and proper bathing and clothing practices, living in crowd and poor ventilated houses, using unsafe and dirty water for bathing, washing clothes, washing utensils etc. may be the prime causes of wide spread women skin diseases in the study area.

Eye Infections: Another common health problem eye disease found among the women of the study area. According to the data, collected from the study area, in average $6.55 \%$ of respondents found suffering from several kinds of eye disorders. The main types of eye complicacies found were night blindness, glaucoma, cataract and corneal opacity as reported by the eye specialist of Chandpur Sadar Hospital. Poor level of nutrition, illiteracy among people, vitamin deficiency, and severe malnutrition are the main causes of eye diseases (Islam, 1996). Again using agricultural residues, biomass fuels for cooking and their smoke from the hearth may contribute for eye infection of household women in the char areas.

Respiratory diseases: It was found that in average of 3.49\% respondent suffering from asthma in the Nilkamal union. Housing factors can play a significant role in respiratory health and greatly exacerbate or increase susceptibility to asthma, allergies, and other respiratory illnesses From the study it was observed that in the char area most of the houses are katcha and made of straw and bamboo which produce much fiber particles. Thus spending a long time in these type of houses can make respondent's hypersensitive to these particles. Besides, these types of houses do not protect them from the cold waves during winter and heat waves during summer, which have profound impact on asthma related problems. 
It might also be true that, women engaged in agriculture related works in the fields are exposed themselves to pollens, dust particles and pesticides. Allergies from these elements might have contributed significantly to increase asthma-related illness, specifically bronchitis and asthma. Besides the women exposed of the smoke from cooking with bio-fuels can lead to respiratory disorders, such as chronic obstructive lung disease in adult women and acute respiratory infections in children, and is a contributory cause of nasopharyngeal cancers.

Gynecological Disease: Malnutrition and unsafe life condition lead to the poor rural women to the miserable sufferings of reproductive health (Ahsan and Rezwana 2005). These women are attacked by various pregnancy related diseases like anemia, mental sickness etc. Sometimes they even cannot identify the diseases and cannot understand physical problems during pregnancy. During expert opinion survey, the gynecologist of Chandpur Sadar Hospital comments, "Expectant mothers suffering from caloric deficiencies which are more vulnerable to death during delivery. As a result, they may face miscarriage or give birth to underweight children." They receive very little attention from their family members during their pregnancy period especially from husbands because they are little aware about the special care of a pregnant mother. Lack of nutritional food for them and their baby, they suffer from many serious diseases and complicacies.

One of the respondent mentioned, "My husband or in-laws did never enquire about my health since I conceived. Instead, they sent me back to my father's house to stay there until delivery. But my parents could not provide me with nutritious food like egg and milk that I needed at that time, because my family is poorer than my husband's family". During the period of pregnancy, they depend on traditional birth attendants ('dai') and local "Kabiraj" and due to lack of proper treatment they face many problems in their future life.

Menstrual Problem and Reproductive Tract Infection (RTI): Menstrual problem and RTI of women are less talked in Bangladesh. However, about $11.48 \%$ surveyed women have mentioned about the diseases which they are facing. At the time of menstruation, lower abdominal pain accompanied by heavy bleeding, white discharges accompanied by abdominal cramps, irregularity of menstruation are some common menstrual problems in the char areas as mentioned by the respondents. But the major concern is that they do not want or hesitate to discuss this issue with any one since according to them these are normal illness. The respondents further added that as they are not always able to get treatment for more serious diseases, they usually avoid these health problems. During FGD, the respondents disclosed that the health problem related to menstrual cycle is often thought as a women's problem which should be kept secret. They further mentioned that in some serious cases they just visit to kabiraj for herbal treatment or use tabij (spiritual 
treatment) from spiritual healers. Need of medical treatment for these health problems might have an impact on their fertility and pregnancy.

From the study it was disclosed that almost all the adolescent girls and women in the char areas use rags for protection during menstruation. These rags are not washed well or never dried properly in the sun because of lack of private places. As a result they often get mildew or fungus leading to reproductive tract infection. No one of the respondent found in the study area to use sanitary method. The respondents added that, this practice is done to save the adolescent girl from embarrassment. Moreover, many social taboos are associated with these rags as found from the above-mentioned study. These unhygienic practices during menstruation may be the consequences of reproductive tract infection in the study area.

Factors Responsible for Major Health Problems of Women in the Study Areas: Many different factors affect women's health, all of them are interrelated (Smyke 1991 and Lawlor et al. 2002). In Bangladesh, women get lesser share in the distribution of food, especially of protein and other health and nutrition related services compared to those of men. Chen et.al., (1981), focused on six biases in family food allocation in Matlab thana of Chandpur District where per capita calorie intake of male averaged 1,599 k.cal. whereas for female it was $1,297 \mathrm{k} . c a l$. The reduced calorie intake for women was found to be person in all age groups which was also reflected in higher incidence of malnutrition. The consequences of under-nutrition are serious, long-term, intergenerational and mostly irrevocable, resulting in increased morbidity and mortality, increased disease burden, and decreased IQ, physical capacity, and productivity. All of these have negative effects on income and economic growth of country (HSB 2011).

The low health status and health problems of women in the rural char areas of Chandpur district are the consequences of a number of social and environmental factors which have brought to light from the study. From the discussion with the focus group the factors identified as extreme poverty, lack of education and awareness, some backward social practices or misconceptions, negligence to women etc. The women in the study area found overburdened with work, tired, most are anemic and lack of personal attention about health and health care. Besides, extreme poverty does not allow themselves to facilitate with disease diagnose, better treatment and having medicine. Thus diseases become chronic and they are to survive by hiding the diseases or with the diseases.

From the field observation, it was realized that early marriage, repeated child bearing, ignorance, poverty and manual labor all have deleterious effects on women health in the remote rural char areas of Chandpur district. It is also clear from the study that women's health and their special needs are often been ignored by the family head and social leaders. 
The wide spread malnutrition and diseases of women that is evident from the present study not only highlights the extreme poverty in the remote char areas but also shows the negligence and discrimination towards women. In addition to that, illiteracy, lack of awareness, misconception, superstitious believes and above all lack of health care facilities contribute a great for poor health scenario and disease causing of women in the remote rural char area of Bangladesh.

One female health worker can change the scenario of women health of a union through motivation, creating awareness, giving tips of hygiene ness and reproductive health and at the same time providing simple medicines for some common health problems. With appropriate training and supportive supervision, these government health workers could deliver a broader range of essential service package to the poorest of the poor char women of remote rural areas.

Media can play a great role in this regard. Local administration can arrange community radio listening program to aware the inhabitants of the remote char areas especially the women.

\section{References}

Ahsan, R.M. and Nahid Rezwana. 2005. Reproductive Health Problems of Poor Women in Tongi Slums and Two Villages of Gazipur District: A Geographic Analysis. In Rosie Majid Ahsan et.al. (ed.) Gender Geography A Reader: Bangladesh Perspective, Bangladesh Geographical Society, pp. 99-122.

Allen, L. H. 2000. Anemia and iron deficiency: effects on pregnancy outcome, The American Journal of Clinical Nutrition. 71 (suppl): 1280S-4S

Aziz, K. M. A., B. A. Hoque, S. R. A. Huttly, K. M. Minnatullah, Z. Hasan, M. K. Patwary, M. M. Rahaman and S. Cairncross. 1990. Water Supply, Sanitation and Hygiene EducationReport of a Health Impact Study in Mirzapur, Bangladesh; Water and Sanitation Report Series-1, Washington, D.C., U.S.A., pp.1-83.

Blair, P. W. (ed.). 1980. Health Needs of the World's Poor Women. Equity Policy Center, Washington, D.C. pp.171-173.

Chen, L. C., E. Huq and S. d'Souza. 1981. Sex Bias in the Family Allocation of Food and Health Care in Rural Bangladesh, Population and Development Review 7 (1), pp. 55-70

Health and Science Bulletin (HSB). 2011. An overview under-nutrition in Bangladesh, ICDDR'B, Dhaka, 9(1): 9-10.

Helweg-Larsen, K. and M. Kruse. 2003. Violence against women and consequent health problems: a register-based study, The Scandinavian Journal of Public Health, 31: 51-57.

Karmakar, R. 2005. Health for All: Need More Emphasis on Women, Steps Towards Development, Dhaka, 4:6-9.

Koenig, M. A., S. Ahmed, M. B. Hossain and A. B. M. K. A. Mozumder. 2003. Women's status and domestic violence in rural Bangladesh: Individual- and community-level effects, Demography, 40 (2): 269-288.

Lawlor, D. A., M. Taylor, C. Bedford and S. Ebrahim. 2002. Is housework good for health? Levels of physical activity and factors associated with activity in elderly women: Results from 
the British Women's Heart and Health Study, Journal of Epidemiology and Community Health, 56: 473-478.

Navarro, V. and L. Shi. 2001. The political context of social inequalities and health, Social Science and Medicine, 52 (3): 481-491.

Perry, H. B. 2000. Health for All in Bangladesh: Lessons in Primary Health Care for the Twenty First Century, UPL, Dhaka. pp. 298-301.

Smyke, P. 1991. Women and Health, Women and World Development Series, London, Zed Books Ltd. pp. 182.

WhittleWhittle, K. L. and M. C. Inhorn. 2001. Rethinking Difference: A Feminist Reframing of Gender/Race/Class for the Improvement of Women's Health Research, International Journal of Health Services, 31: 147-165.

WHO 2013. Women and Health, Global Health Observatory, World Health Organization, Geneva. 